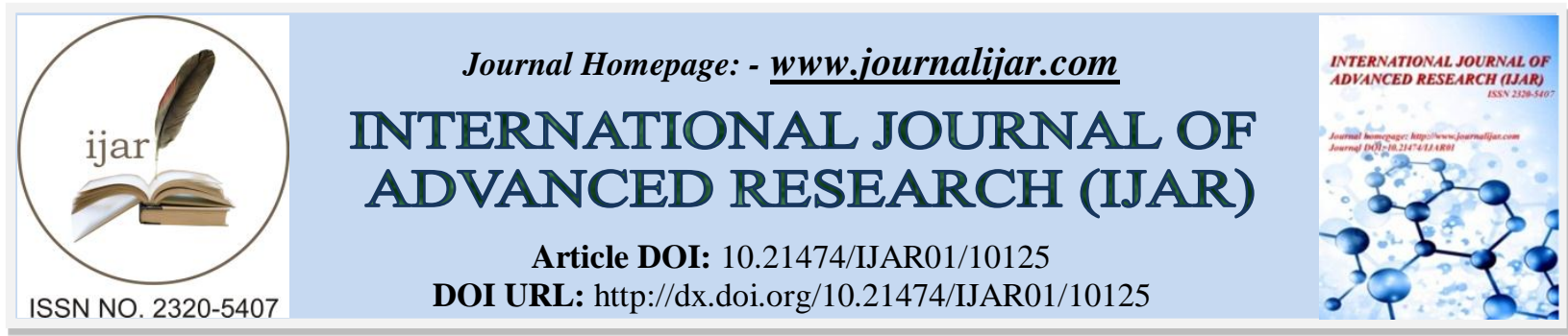

RESEARCH ARTICLE

\title{
ORAL HEALTH KNOWLEDGE AND PRACTICE AMONG INTERMEDIATE SCHOOL CHILDREN IN
} TAIF CITY, SAUDIARABIA.

\author{
Mohammed Wael Bassuoni ${ }^{1}$, Ahmed Abdulhalim Turkistani ${ }^{2}$, Abdulrahman Hani Sabbagh ${ }^{2}$, Mutaz Fahad \\ Felemban ${ }^{2}$, Talal Mastour Alqurashi ${ }^{2}$ and Khalid Hussain Alghamdi ${ }^{2}$. \\ 1. Associate Professor of Community and Preventive Dentistry, Faculty of Dentistry, Taif University, Taif, \\ Kingdom of Saudi Arabia. \\ 2. BDS, Faculty of Dentistry, Taif University, Taif, Kingdom of Saudi Arabia.
}

\section{Manuscript Info}

…………………...

Manuscript History

Received: 01 October 2019

Final Accepted: 03 November 2019

Published: December 2019

Key words:-

Oral Health, Knowledge, Practice,

Intermediate Schoolchildren, Taif.

\section{Abstract}

Aim : To assess the knowledge and practice of oral health among intermediate schoolchildren in Taif city, KSA.

Introduction : Oral health knowledge is an important factor to maintain a healthy oral condition, However, without interpreting this knowledge into practice, maximum oral health will not be achieved.(1) An essential fact for humans to be in a healthy state and well-begin is to have a proper oral health, this can be achieved by knowing and practicing oral hygiene methods in a good manner.

Materials and methods : This study started by taking the approvals from the randomly selected schools and giving the choice for the students to complete the questionnaire was considered as an approval to participate in the project, the questionnaires were distributed among 394 participants divided to males and females, The collected data was include: demographic variables, Oral health knowledge and practice close ended and multiple choice questions, Statistical analysis was performed by (SPSS 20.0).

Results: The results of the study shows most of the participants weren't aware that the tooth decay can affect their general health, while the majority of the respondents brush their teeth twice a day, Moreover there was statistically significance difference with $(P=, 000)$ when comparing the knowledge between male and female which shows that the female participants have better knowledge regarding their oral health than male. And also there was a significance difference when comparing the knowledge between students of different socioeconomic status ( Private $\backslash$ Govermental schools ) with $(\mathrm{P}=, 000)$ It was seen that private school students have good knowledge in compare to governmental students.

Conclusion: The results of this study shows that the level of oral health knowledge and practice still below satisfaction, so the

Corresponding Author:-Mohammed Wael Bassuoni.

Address:-Associate Professor of Community and Preventive Dentistry, Faculty of Dentistry, Taif University, Taif, Kingdom of Saudi Arabia. 
implementation for further preventive dental public health programs and the involvement of more oral health education programs in the school curriculum can play an important role to improve their knowledge and awareness.

Copy Right, IJAR, 2019,. All rights reserved.

\section{Introduction:-}

Oral health knowledge is an important factor to maintain a healthy oral condition, However, without interpreting this knowledge into practice, maximum oral health will not be achieved.(1) An essential fact for humans to be in a healthy state and well-begin is to have a proper oral health, this can be achieved by knowing and practicing oral hygiene methods in a good manner.(2) Proper oral health is obtained through maintenance of the oral functions with good esthetic appearance. The most common public health problems are oral diseases due to its high prevalence and incidence, especially in a low income populations. $(3,4)$ Moreover poor oral health is 12 times more likely to limit children's daily activity, such as going to school, In contrast to children with good oral health practice, More than 50 million hours per year are lost in schools because of oral diseases. (5)Additionally from 60-90\% of schoolchildren and adults in the world have an experience with caries especially in Asian and Latin American countries.(6) Sa'adu et al. (2012) stated that caries is five times more common than asthma, and seven times more common than hay fever, they argued that ,in order to prevent common oral diseases, specific measures such as regular tooth brushing and flossing, fluoridation, sealants, healthy nutritional habits and regular dental attendance must be promoted and encouraged. (7)By understanding and implementation of appropriate oral hygiene practices we can reduce oral problems. Oral practice: This is an activity undertaken by people in order to protect, promote, or maintain oral health and prevent dental diseases, The practices include tooth brushing and sugar consumption practice among others.(8)

Although the practice including different methods that can keeps the mouth and teeth free of diseases such as cavities and gingivitis.(9) Taif city is a city in the kingdom of SaudiArabia ,Belongs to Mecca province with altitude of $(6,165 \mathrm{ft})$ and a population of about 1,200,000people (10). Recent studies conducted in Taif showing high caries prevalence among primary schoolchildren with an aged ranged from 6-12, also other research applied upon 18 years old and older concluded the same results in patient attending Taif University Outpatient Clinics (TUOC).(11,12) Based on these studies there is an increase of caries prevalence in Taif in different age that's indicate the low level of oral health knowledge and the preventive measures. The main aim of this study is to assess the knowledge and practice of oral health among intermediate schoolchildren in Taif city. In addition, it is anticipated to be a reference for future research to compare knowledge and practice of oral health among other schoolchildren's in different societies.

Aim:-

To assess the knowledge and practice of oral health among intermediate schoolchildren in Taif city.

\section{Materials And Methods:-}

\section{Ethics and approvals :-}

The study was supported and approved by Taif university, Faculty of dentistry. And the approval of the schools in which the sample are collected was taken by a letter sending to each school describing the purpose of the study including the procedures that will applied during the conduct, Completing the questionnaire is considered to be a consent and approval to participate in this study.

\section{Study populations and sampling-}

The study took place between February and March 2017, For intermediate schoolchildren in Taif city. Then schools were chosen randomly to conduct the study in, one public and one private school for male participants and same for females from different neighborhoods in Taif. A descriptive cross sectional study was conducted among intermediate schoolchildren with a total of 400 participants divided by half for both males and females. While Intermediate schools in Saudi Arabia include students in seventh to ninth grades. So the inclusion criteria were students aged from 12-16 ( seventh to ninth grades ) as they are aware enough to answer the questions in the questionnaire. In addition, In general most of them have an experience with oral problems. A day chosen by a principal of each school to visit the school and given about 1 hour for data gathering. 


\section{Questionnaire method:-}

A questionnaire with closed ended questions was used to collect data from participants, The questionnaire is a researcher designed written in English with an 18 items categorized to evaluate knowledge and practices related to oral health. So that it has been divided into 3 sections, the first section is covering the demographic variables ( Age, gender, socioeconomic level ) Then the second section is about oral health knowledge including general information about the causes of caries and the relation between oral health to general health and aesthetics, while the third section were about the practices of oral hygiene such as frequency, duration of brushing and method used to clean their teeth. Prior to start the study the students received an information by the investigator describing the purpose of this study and explaining the questionnaire, However, the survey were filled through intervie ws by a well-trained investigators through asking the students the questions with forced choices either Yes\No or multiple choices translating for them to Arabic and then put their responses in the survey application which is designed in Google Forms application,(13) In which all the responses automatically saved, with average time of 2 minutes to complete the survey for each participant.

\section{Statistical analysis:-}

Statistical analysis t-test were performed using Statistical Package for Social Sciences version 20 ( SPSS 20.0 Inc.,IL ).

\section{The Results:-}

In this study, Data were gathered from 394 participants ( 53\% Male and 47\% Female ), Moreover the participants were categorized to high and low socio-economic status based on the fees for private schools of which $200(51.5 \%)$ participants studying in private school and the other 195 ( 48.5\%) of the students studying in the governmental school, Most of the students 53\% were from 12-14 Years age group, while 47\% were from 15-16 Years age group.

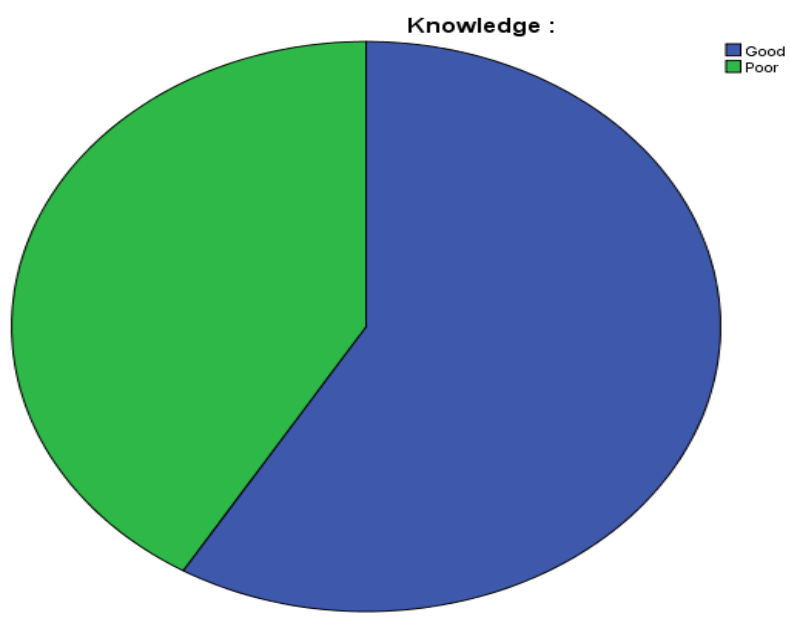

Knowledge of oral and general health ( Table 1 ) :-

Most of the students (92.6\%) knew that sweets cause caries and (78.9\%) knew that sour drinks are also one of the causes of caries, About (59.9\%) of the study population were aware of that tooth decay can affect their general health, while the rest $(40.1 \%)$ say's that there's no effect of tooth decay to their general health, Approximately $(82.5 \%)$ of subjects reported that tooth decay can affect their aesthetic appearance, And $(60.4 \%)$ of children understand that the fluoride is a mineral which enhance tooth strength, And $(49.7 \%)$ knew that water and dental products are sources of fluoride, It was seen that only (12.9\%) aware about the correct number of deciduous teeth, And for permanent teeth $(37.1 \%)$ of study population knew the correct number.

Table 1:- Knowlege

\begin{tabular}{|c|c|c|c|}
\hline & & $\mathrm{N}$ & $\%$ \\
\hline \multirow[t]{2}{*}{ Are sweets cause caries? } & No & 29 & $7.4 \%$ \\
\hline & Yes & 365 & $92.6 \%$ \\
\hline Are sour drinks cause caries? & No & 83 & $21.1 \%$ \\
\hline
\end{tabular}




\begin{tabular}{|c|c|c|c|}
\hline & Yes & 311 & $78.9 \%$ \\
\hline \multirow{2}{*}{$\begin{array}{l}\text { Is tooth decay affects the } \\
\text { general health? }\end{array}$} & No & 158 & $40.1 \%$ \\
\hline & Yes & 236 & $59.9 \%$ \\
\hline \multirow{2}{*}{$\begin{array}{l}\text { Is tooth decay affects the } \\
\text { aesthetics appearance? }\end{array}$} & No & 69 & $17.5 \%$ \\
\hline & Yes & 325 & $82.5 \%$ \\
\hline \multirow{2}{*}{$\begin{array}{l}\text { Fluoride is mineral that enhance } \\
\text { teeth strength }\end{array}$} & No & 156 & $39.6 \%$ \\
\hline & Yes & 238 & $60.4 \%$ \\
\hline \multirow{4}{*}{$\begin{array}{l}\text { What are the sources of the } \\
\text { fluoride? }\end{array}$} & Fast foods & 11 & $2.8 \%$ \\
\hline & Sweets and chocolates & 19 & $4.8 \%$ \\
\hline & Water and dental products & 196 & $49.7 \%$ \\
\hline & Don't know & 168 & $42.6 \%$ \\
\hline \multirow{4}{*}{$\begin{array}{l}\text { The deciduous teeth, How } \\
\text { many are they? }\end{array}$} & 16 & 137 & $34.8 \%$ \\
\hline & 18 & 140 & $35.5 \%$ \\
\hline & 20 & 51 & $12.9 \%$ \\
\hline & 22 & 66 & $16.8 \%$ \\
\hline \multirow{4}{*}{$\begin{array}{l}\text { The permanent teeth, How } \\
\text { many are they? }\end{array}$} & 28 & 128 & $32.5 \%$ \\
\hline & 30 & 68 & $17.3 \%$ \\
\hline & 32 & 146 & $37.1 \%$ \\
\hline & 34 & 52 & $13.2 \%$ \\
\hline \multirow[t]{2}{*}{ *Knowledge } & Good & 231 & $58.6 \%$ \\
\hline & Poor & 163 & $41.4 \%$ \\
\hline
\end{tabular}

In the present study, we divide the sample into participants with either good or poor knowledge through checking their responses if they answers half or more of questions related to knowledge of oral health we consider them to have a good knowledge, And in return for whom answer less than half of these questions we consider them to have a poor knowledge.

There was statistically significance difference with $(\mathrm{P}=, 000)$ when comparing the knowledge between male and female which shows that the female participants have better knowledge regarding their oral health than male. And also there was a significance difference when comparing the knowledge between students of different socioeconomic status ( Private $\backslash$ Govermental schools ) with $(\mathrm{P}=, 000)$ It was seen that private school students have good knowledge in compare to governmental students ( Table 2 ).

Table 2:- Knowledge

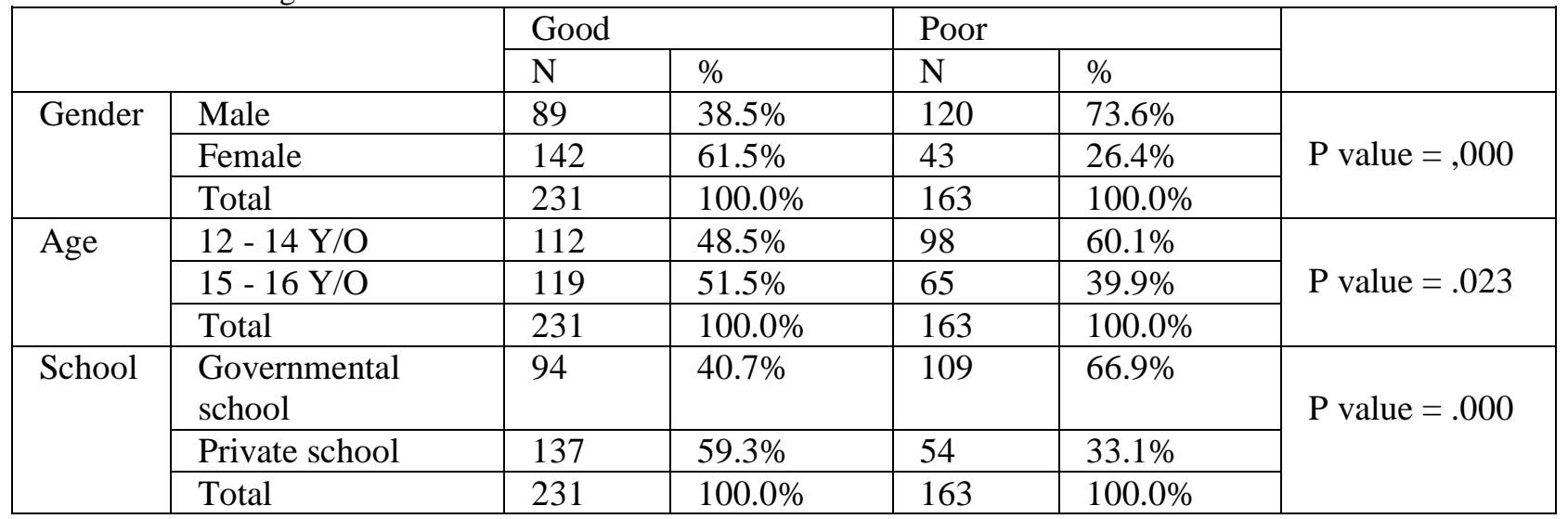




\section{Awareness of oral hygiene practices ( Table 3 ) :-}

In our study the oral hygiene practices indicated that $(44.4 \%)$ of participants would brush their teeth twice per day, whereas $(25.6 \%)$ would brush only once daily, while $(20.1 \%)$ of children would brush their teeth more than two times per day. About (28.7\%) would like to brush their teeth in the early morning, while (24.6\%) brush their teeth before sleep, Also (14.2\%) of children would prefer to brush their teeth after meals, Finally there were students who don't have a specific time to brush their teeth who are estimated $(32.5 \%)$ of total study population. It was seen approximately (90.6\%) of the children used tooth brush with paste to clean their teeth. Also it was observed that (28.9\%) of students were brush their teeth using horizontal technique, while $(23.6 \%)$ using vertical technique, and $(17.5 \%)$ prefer the circular motion technique, and some of the student (29.9\%) doesn't use a specific technique for brushing. The students were asked about the type of brush used most of them ( $38.1 \%)$ using soft brush , and (34.5\%) were using medium brush, and (12.4\%) prefer the hard brush, finally (15\%) of the students doesn't care about the type of their brush. When subjects were asked for the appropriate consumed time for brushing (34\%) says they brush their teeth for $2 \mathrm{~min}$, and (31.5\%) prefer to brush for only one min, while (24.6\%) would brush their teeth for more than $2 \mathrm{~min}$, and some of the participants (9.9\%) brush for less than one min. Then the students were asked about the role of their parents towards their daily oral hygiene care, majority of the children (40.9\%) says that their parents doesn't care, and (38.1\%) answered that their parents only advising them without watch, while ( $12.9 \%)$ of them their parents teaching and watching them at the same time, whereas $(8.1 \%)$ their parents only watching without advising them.

Table 3:- Practice

\begin{tabular}{|c|c|c|c|}
\hline & & $\mathrm{N}$ & $\%$ \\
\hline \multirow{4}{*}{$\begin{array}{l}\text { How many times do you brush } \\
\text { your teeth? }\end{array}$} & One time daily & 101 & $25.6 \%$ \\
\hline & Two times daily & 175 & $44.4 \%$ \\
\hline & More than two times daily & 79 & $20.1 \%$ \\
\hline & Doesn't brush at all & 39 & $9.9 \%$ \\
\hline \multirow{4}{*}{$\begin{array}{l}\text { When do you brush your teeth } \\
\text { usually? }\end{array}$} & At early morning & 113 & $28.7 \%$ \\
\hline & After meals & 56 & $14.2 \%$ \\
\hline & Before sleep & 97 & $24.6 \%$ \\
\hline & No specific time & 128 & $32.5 \%$ \\
\hline \multirow{4}{*}{$\begin{array}{l}\text { What do you use to clean your } \\
\text { teeth? }\end{array}$} & Brush with toothpaste & 357 & $90.6 \%$ \\
\hline & Dental floss & 1 & $0.3 \%$ \\
\hline & Sewak & 32 & $8.1 \%$ \\
\hline & Mouthwash & 4 & $1.0 \%$ \\
\hline \multirow{4}{*}{$\begin{array}{l}\text { What is the technique used to } \\
\text { brush your teeth? }\end{array}$} & Side to side (Horizontal) & 114 & $28.9 \%$ \\
\hline & Up down (Vertical) & 93 & $23.6 \%$ \\
\hline & Circular motion & 69 & $17.5 \%$ \\
\hline & Mixed motions & 118 & $29.9 \%$ \\
\hline \multirow[t]{4}{*}{ What is the type of your brush? } & Hard (rough) & 49 & $12.4 \%$ \\
\hline & Soft & 150 & $38.1 \%$ \\
\hline & Medium & 136 & $34.5 \%$ \\
\hline & Don't know & 59 & $15.0 \%$ \\
\hline \multirow{4}{*}{$\begin{array}{l}\text { What is the consumed time for } \\
\text { brushing? }\end{array}$} & 1 Minute & 124 & $31.5 \%$ \\
\hline & 2 Minutes & 134 & $34.0 \%$ \\
\hline & More than 2 Minutes & 97 & $24.6 \%$ \\
\hline & Less than one minute & 39 & $9.9 \%$ \\
\hline \multirow{4}{*}{$\begin{array}{l}\text { What is the role of your parents } \\
\text { ? }\end{array}$} & Watching you while brushing & 32 & $8.1 \%$ \\
\hline & $\begin{array}{l}\text { Teaching you the brushing } \\
\text { technique without watching }\end{array}$ & 150 & $38.1 \%$ \\
\hline & $\begin{array}{l}\text { Teaching and watching you } \\
\text { while brushing }\end{array}$ & 51 & $12.9 \%$ \\
\hline & They don't care & 161 & $40.9 \%$ \\
\hline
\end{tabular}




\section{Discussion:-}

The oral health knowledge and the awareness of oral hygiene practices plays an important role to avoid many of future problems and also to enhance the self-confidence through maintaining the esthetic appearance.

So, In the present study, we used to evaluate and provide data about the oral health knowledge and practices among intermediate schools children with age ranged from 12-16 years old comparing their knowledge levels between different variables including ( Gender, Socio-economic status, Age ) in Taif city in the western region of Saudi Arabia. Moreover, to the best of our knowledge there was no study conducted aims to evaluate the level of knowledge and practices of oral health within this age group in the western region of KSA, Regarding the oral health knowledge it was seen that most of intermediate school children $(92.6 \%) \mathrm{knew}$ that sweets are one of the causes of caries and also ( $78.9 \%$ ) of students agree about sour drinks can cause caries which is agree with a study conducted in the north of Jordan by al-Omiri et.al.(13) Which seems that the educational programs level in Jordan about oral health knowledge are near to that in KSA. Approximately (59.9\%) of children agree about that tooth decay can affects their general health which less comparable with an Indian study conducted in Chennai city,(14) And this issue indicate a major problem in the sampled students because many of systemic disease signs appears first in the oral cavity so they have to be aware of them.(15) Moreover, the surprising findings shows that (82.5\%) of children were unaware of that caries may affects their aesthetics appearance which is opposite to what was seen in North of Jordan, and Chennai in India. $(13,14)$ Also many of the students $(39.6 \%)$ were confused about what is the fluoride and it's important in enhancing teeth strength, which is similar to the Jordanian study findings.(13)In addition the main weakness of the sampled students were observed when we ask them about the number of the primary teeth only (12.9\%) of them are knew the correct number, but still better than an Indian study which shows that only $(9 \%)$ knew the correct number.(14)Moreover, We noticed a high difference with $(\mathrm{P}=, 000)$ which shows that Women had a higher level of knowledge $(61.5 \%)$ in compare to Men taken in consideration that Women sample $(\mathrm{N}=185)$ were less than $\mathrm{Men}(\mathrm{N}=209)$, As well as private school children were also shows a better level of knowledge $(59.3 \%)$ in parallel with governmental school children with $(\mathrm{P}=, 000)$ which may be reflects the level of the parents attitudes towards their children in regard to oral health knowledge and practices . While there was no obvious differences between different age groups $(\mathrm{P}=0.23)$ which means that all intermediate school children are about the same level knowledge of oral health. Regarding tooth brushing most of the subjects (44.4\%) brushings their teeth twice a day but its still better than another study findings conducted to intermediate school children in the middle region of Saudi Arabia(2001-2002) which shows (38\%) of the students brushing twice per day, knowing that their study sample were $(\mathrm{N}=553)$, that's indicate the knowledge of intermediate school children about oral health practices in the western region are better than the middle region of KSA (Riyadh city).(16) while the results of a Malaysian study shows better practice of brushing frequency by (50.8\%) of their samples students were brushing at least two times per day.(17) Moreover, Increasing the frequency of brushing will decrease plaque accumulation and gingival problems, so the children must be aware about the importance of brushing frequency and it's effect on their oral and gingival health.(18)Unfortunately many of the sampled children (32.5\%) had no specific time for brushing or doesn't care about a particular time for brushing in their daily routine. Majority of the sampled students(90.6\%) were use a tooth brush with toothpaste to clean their teeth and this finding is similar to a result reported by WHO (83\%).(19) Also an incitement findings shows that most of the students are ranged between the usage of soft(38.1\%) and medium(34.5\%) tooth brush bristles. Finally a regrettable findings $(40.9 \%)$ shows lack of parental motivations and advises to their children regarding the oral hygiene practice, this facts reflects the awareness level of the parents about the importance of oral hygiene practice specially tooth brushing which plays an important measure in promoting the overall oral health.(20)

\section{Potential limitations:-}

We depend on an interview method during the collection of the data in order to solve the problem if the students doesn't understand the question clearly we can repeat it again with different style. Moreover, the present study giving an information regarding only a special age groups, So it's important to conduct more comprehensive study to reflects the population more accurately, however we believe that the study sample was sufficiently large enough to reflect this age group in Taif city taken into consideration the random selection of the schools and drawn from economically diverse area thus to be more representative of other regions in KSA. 


\section{Conclusion :-}

The results of this study shows that the level of oral health knowledge and practice still below the satisfaction, so the implementation for further preventive dental public health programs and the involvement of more oral health education programs in the school curriculum can play an important role to improve their knowledge and awareness.

\section{Acknowledgement:-}

We would like to thank Abdullah Mohammed Turkistani, Majed Zaki Bahader and Mohammed Abdullah Alghalbi for helping us to complete this research as a data collectors.

\section{References:-}

1. McGrath C, Sham AS, Ho DK, Wong JH. The impact of dental neglect on oral health: A population based study in Hong Kong. Int Dent J 2007;57:3-8.

2. Kenneth W. Norwood, Jr, MD, Rebecca L. Slayton, CLINICAL REPORT, Oral Health Care for Children With Developmental Disabilities,American academy of pediatric, Guidance for the Clinician in Rendering Pediatric Care, Volume 131, Number 3, March 2013.

3. Chi DL, Masterson EE, Carle AC, Mancl LA, Coldwell SE: Socioeconomic status, food security, and dental caries in US children: mediation analyses of data from the National Health and Nutrition Examination Survey, 2007-2008. Am J Public Health. 2014, 104 (5): 860-864. 10. US General Accounting Offices.

4. Jiang H, Petersen PE, Peng B, Tai B, Bian Z: Self-assessed dental health, oral health practices, and general health behaviors in Chinese urban adolescents. Acta Odontol Scand. 2005, 63: 343-352.

5. Oral Health: Dental Disease is a Chronic Problem among Low-Income Populations. Washington, DC:Report to Congressional Requesters; 2000.

6. Petersen PE, Bourgeois D, Ogawa H, Estupinan-Day S, Ndiaye C. The global burden of oral diseases and risks to oral health. Bull World Health Organ 2005;83:661-9.

7. Sa'adu, L., Musa, O. L., Abu-Saeed, K. \& Abu-Saeed, M. B. (2012). Knowledge and practice on oral health among Junior Secondary School Students in Ilorin West Local Government Area of Nigeria. E-journal of Dentistry, 2(2), 170-175.

8. Juliana O. Taiwo1* Olusola Ibiyemi2 Olubunmi Bankole3.(2012) Oral Health Attitudes and Practices of the Elderly People in South East Local Government Area (SELGA) In Ibadan. Journal of Biology, Agriculture and Healthcare. Vol 2, No.4, 2012,P:53-59.

9. "Health topics: Oral health". World Health Organization (WHO). Retrieved 6 March 2015.

10. "Brief about Ta'if City". Ta'if $\quad$ Retrieved April 26, 2016.http://www.taifcity.gov.sa/pages/\%D9\%86\%D8\%A8\%D8\%B0\%D8\%A9-\%D8\%B9\%D9\%86\%D8\%A7\%D9\%84\%D8\%B7\%D8\%A7\%D8\%A6\%D9\%81-57.aspx

11. Al Shamrani A.S1, Bassuoni, M.W2, Mohamed, M.A3, Mohamed, R.N4, Hussein, Y.M5.(2015) Caries Prevalence and Treatment Need Among Primary School Children in Taif, Saudi Arabia. Indian JOURNAL OF APPLIED RESEARCH.VOL : 5,ISSUE: 7,P:326-328.(2015).

12. Khaled Alswat, ${ }^{A, C}$ Waleed S. Mohamed, ${ }^{A}$ Moustafa A. Wahab, ${ }^{B}$ and Ahmed A. Aboelil ${ }^{\text {B. }(2016)}$ The Association Between Body Mass Index and Dental Caries: Cross-Sectional Study. Journal of CLINICAL MEDICINE RESEARCH. J CLIN MED RES. 2016;8(2):147-152.

13. Al-Omiri MK, Al-Wahadni AM, Saeed KN. Oral health attitudes,knowledge, and behavior among school children in North Jordan. J Dent Educ 2006;70:179-87.

14. Priya M, Kanagharekha Devads, Deepti Amarlal, Venkatachalapathy A.(2013)Oral health attitudes, knowledge and practice among school children in Chennai, India. Journal of education and ethics in Dentistry. JanuaryJune 2013,Vol:3, Issue:1, P:26-33.

15. Nitika Jain, Dipika Mitra, KP Ashok, Jyothi Dundappa, Sweta Soni, Sameer Ahmed.(2012) Oral hygiene-awareness and practice among patients attending OPD at Vyas Dental College and Hospital, Jodhpur. Journal of Indian society and periodontology. Y : 2012 Vol : 16, Issue : 4, P : 524-528

16. Salwa A. Al-Sadhan.(2003) Oral health practices and dietary habits of intermediate school children in Riyadh, Saudi Arabia. The Saudi Dental Journal: 15 (2); 81-87.

17. Cheah Whye Liana *, Tay Siow Phingb, Chai Shiun Chata, Bong Cheong Shina, Luqmanul Hakim Baharuddina, Zhuleikha Bainun Jalil Che'Jalila.(2010) Oral health knowledge, attitude and practice among secondary school students in Kuching, Sarawak. Archives of Orofacial Sciences (2010), 5(1): 9-16.

18. Barzan A. Mirza, Vian M. Hussain.(2006) The effect of frequency of tooth brushing on the gingival status among 10-13 years old school children in Dohuk. (J Bagh Coll Dentistry 2006; 18(3)48-50. 
19. Oral Health Status in rural child population: Promotional \&Interventional Strategies. A GOI-WHO Collaborative Programme

20. 2006-07.Available from: http://www.whoindia.org/en/.../Section30_1453.htm. December 2012.

21. Honkala E. Oral health promotion with children and adolescents. In: Shou L, Blikhorn (Edn) .Oral health promotion. Oxford University Press. 1993;p 669-87. 